\section{CLINICAL NEURO-OPHTHALMOLOGY}

By Frank B. Walsh, M.D., F.R.C.S., D.Sc. 2nd edition. Pp. xvi + 1294, with 44I illustrations. London: Baillière, Tindall \& Cox Ltd. 1957. fi I I Is.

This book, by its very size, must be essentially one of reference and there can be few neurological conditions associated in any way with the eyes and their adnexa which are not mentioned in these pages. It is, in fact, a textbook of neurology with special reference to ophthalmology and many subjects are discussed which one would not expect to find in such a work. Each section is complete in itself and is as concise as it should be in a book of this type. Use is made of case summaries to illustrate clinical points and a full bibliography follows most of the sections. This is a feature of particular value and one that is all too often lacking in textbooks. If any one item is to be singled out as especially contributing to the success of such a book, it is the index. It must be possible to refer quickly to the subject of which the reader is desirous of gaining further knowledge and there is a very comprehensive index in this volume which has stood up to repeated testing by the reviewer.

In a review of this length it is not possible to discuss the subject matter in any detail. The relevant anatomy and physiology is not dealt with in a preliminary section, but whenever it is applicable in the text. The chapter on the ocular complications of various drugs and poisons is of particular interest, as many of these are rare and, therefore, not likely to be common knowledge.

In this second edition new information has been added to bring the text up to date, but no fundamental changes have been made. Although there are obvious advantages of keeping this edition in one volume, they have to be weighed against the size of the book, which makes it somewhat difficult to handle. This is in part offset by the attractive format, the division of the pages into three columns making for easy reading. The numerous illustrations are well reproduced and make a considerable contribution in their own right.

The first edition of this book has already proved its worth and undoubtedly it will continue to be a leading authority in its field. It can be unreservedly recommended in the knowledge that any general physician, neurologist or ophthalmologist will seldom appeal to its pages in vain in a search for further knowledge.

N.S.G.

\section{PERSONALITY AND MOTIVATION STRUCTURE AND MEASUREMENT}

By R. B. Cattell. Pp. xxiv +948 , illustrated. London: George G. Harrap \& Co. Ltd. $195^{8}$. $55^{\mathrm{s}}$.

Ever since scientific psychology emerged from the armchair philosophy of the 19 th century attempts have been made to quantify the most variable of all biological concepts-the human personality. Many types of personality classification have been made in the past, which have valuable limited, applications, and the typologies of Jugg, Kretschmer and others are well known to psichiatrists. In the second half of this century, h\&ever, new attempts have been made to analyse the personality into measurable traits by the use $=$ of advanced statistical techniques.

In this country the work of Eysenck on dimensions of psychoticism and neuroticism represents our greatest advance in quantitative psychiatry the United States Professor Cattell has long been the leader of a school of multi-dimensional personality analysis. His work over many years Ppas been crystallized into this great monograph, whळ्षh is a survey of progress in the field of factor-analytic research on basic personality dimensions. It preseats a complete theoretical system justified by researgh findings obtained over 30 years, together with tensive instructions on the practical applications clinical and industrial use.

Covered by 17 chapters arranged under $\stackrel{\$}{\mathbf{s j x}}$ headings, the book discusses basic principles off personality research, the structure of source tracts, such as cyclothymia, intelligence, ego-strength, etæ; theoretical integration of formal models; ge measurement of attitudes, motivation and adjustment; personality change in anxiety, fatigue aqd psycho-physiological states; and new test te niques in clinical educational and industrial psychology.

Written expressly for academic teaching an $\frac{0}{\mathbb{Q}}$ for the practising psychologist, this is a highly tech text which to be useful demands at least a ground knowledge of factor analysis. Psychiatrits of the new school who are already using this techisnique will find this work of inestimable value. Tक्षिe future of psychiatric diagnosis and nosology undoubtedly lies in the direction which Professir Cattell has so ably pioneered, and those in the vanguard can have no better guide that this magnim opus.

L.R.C.H.

\section{IDEALS IN MEDICINE}

\section{A Christian Approach to Medicine}

Edited by Vincent EDMunds, M.D., M.R.C.P, and C. Gordon Scorer, M.B.E., M.D., F.R.C.ङ. Pp. 192. London: The Tyndale Press. I958. I 2s. $6 \mathrm{~d}$.

A symposium by members of the Christia Medical Fellowship specializing in most fields of medicine. It is addressed to the newly qualified convinced Christian doctor who needs guidance the ethical problems which confront him as one who believes in the immortality of the soul and the necessity of salvation. Such subjects as the doctor patient relationship, Christian psychiatry and mo controversial topics, such as contraception, euthanasia and faith healing are dealt with in a restraine and thoughtful way.

The final-year student and graduate who does not share the religious views of the authors shour find much that will stimulate thought regarding 